\title{
Studies on the neural mechanisms of baitshyness in rats
}

\author{
BRYAN KOLB \\ University of Lethbridge, Lethbridge, Alberta, Canada TIK $3 M 4$
}

ARTHUR J. NONNEMAN

University of Kentucky, Lexington, Kentucky 40506

and

\author{
PAUL ABPLANALP \\ Massachusetts College of Optometry, 424 Beacon Street, Boston, Massachusetts 02115
}

\begin{abstract}
The effects on taste aversion learning of lesions in a variety of brain areas known to alter taste avoidance and/or shock avoidance behavior were examined in 72 adult male rats. Bilateral lesions of the medial frontal cortex, orbital or sulcal frontal cortex, cingulate cortex, caudate nucleus, medial thalamus, or hippocampus failed to significantly alter taste aversion learning, while bilateral lesions to the amygdala impaired this learning. Lesions to the septum produced equivocal results. There does not appear at present to be a general conceptual framework that can account for the data described here as well as do previous studies in the literature.
\end{abstract}

Rats exhibit two adaptive specializations of food gathering behavior, neophobia and baitshyness. Neophobia refers to the tendency of rats to consume less of novel food items than familiar ones, while baitshyness or taste aversion refers to the ability of rats to readily associate distinctive flavors with subsequent illness so that they will avoid ingestion of the food on later occasions (Rozin \& Kalat, 1971). Taste aversion learning is a distinctive type of learning in that the stimulus-response (poison-illness) association is rapid (frequently requiring only one trial) and occurs even if the delay between the ingestion of the food and the illness is as long as $12 \mathrm{~h}$ or more. Rozin and Kalat (1971) have suggested that the "laws" of this sort of learning need not necessarily be the same as those for other, more conventional avoidance problems, and it follows that the central nervous system mechanisms mediating taste aversion learning need not necessarily be the same as those mediating other behaviors (McGowan, Garcia, Erwin, \& Schwartz, 1969; Miller, Elkins, \& Peacock, 1971). Indeed, the unique combination of ingestive and avoidance behaviors in taste aversion learning might suggest that flavor-illness associations are mediated by structures known to be involved in the regulation of both eating and avoidance behaviors. Although lesions to a large number of nervous structures are known to alter normal food regulation and/or avoidance learning, little is known about the effects of lesions in these structures on taste aversion learning. It has, however, been reported that animals with lesions to the dorsal hippocampus (Best \& Orr, 1973), amygdala (McGowan, Hankins, \& Garcia, 1972), lateral hypothalamus (Roth, Schwartz, \& Teitlebaum,

This research was supported by NRC grants to B. Kolb and C. H. Vanderwolf and an N.I.M.H. grant to A. J. Nonneman.
1973), ventromedial hypothalamus (Gold \& Proulx, 1972), or olfactory bulbs (Hankins, Garcia, \& Rusinak, 1973) are impaired at taste aversion learning. The primary purpose of the current research was to extend such observations to a variety of frontolimbic structures that are known to alter avoidance and/or ingestive behavior, including medial frontal cortex, orbital frontal cortex, cingulate cortex, head of the caudate nucleus, medial thalamus, hippocampus, septum, and amygdala. A secondary purpose of this study was to verify the previously cited results within one study, using a single experimental paradigm. We hoped that this would allow a better assessment of the relative effectiveness of lesions in the various structures than can be gained from a comparison of results across studies.

\section{METHOD}

\section{Subjects}

The subjects were 72 male hooded (Long-Evans) rats aged roughly 90 days at the time of surgery. The rats were housed individually in wire mesh cages and were maintained ad lib on a diet of Purina Lab Chow.
Surgery
The operations were performed under sodium pentobarbital anesthesia $(50 \mathrm{mg} / \mathrm{kg})$. The controls were anesthetized, the scalp was incised and then closed with wound clips. The medial frontal and sulcal frontal lesions were intended to remove by aspiration the respective cortical projection fields of thalamic nucleus medialis dorsalis as defined by Leonard (1969) (for more details see Nonneman, Voigt, \& Kolb, 1974) while the cingulate lesions were intended to remove by aspiration the cingulate cortex as defined by Domesick (1969). All other lesions were produced electrolytically using the coordinates and current parameters shown in Table 1. Lesions were made by an anodal dc current passed through an insulated $.5-\mathrm{mm}$ stainless steel wire that had a $.5-\mathrm{mm}$ uninsulated tip. An anal electrode served as the cathode. 
Table 1

Summary of Surgical Procedures

\begin{tabular}{lll}
\hline \multicolumn{1}{c}{ Group } & \multicolumn{1}{c}{ Coordinates } & Time and Current \\
\hline Caudate & 1) L $2.2 \mathrm{~mm}, \mathrm{AP}+0.5 \mathrm{~mm}, \mathrm{~V} .5 .5 \mathrm{~mm}$ & $3 \mathrm{~mA}$ for $15 \mathrm{sec}$ \\
Medial Thalamus & 2) L $2.2 \mathrm{~mm}, \mathrm{AP}+1.5 \mathrm{~mm}, \mathrm{~V} 5.5 \mathrm{~mm}$ & $3 \mathrm{~mA}$ for $15 \mathrm{sec}$ \\
& 1) L $0.8 \mathrm{~mm}, \mathrm{AP}-2.0 \mathrm{~mm}, \mathrm{~V} 6.5 \mathrm{~mm}$ & $2.5 \mathrm{~mA}$ for $20 \mathrm{sec}$ \\
Amygdala & 1) L $4.0 \mathrm{~mm}, \mathrm{AP}-0.5 \mathrm{~mm}, \mathrm{~V} 8.0 \mathrm{~mm}$ & $2.0 \mathrm{~mA}$ for $20 \mathrm{sec}$ \\
& 2) L $4.0 \mathrm{~mm}, \mathrm{AP}-1.0 \mathrm{~mm}, \mathrm{~V} 8.5 \mathrm{~mm}$ & $2.0 \mathrm{~mA} \mathrm{for} 20 \mathrm{sec}$ \\
Septum & 3) L $4.0 \mathrm{~mm}, \mathrm{AP}-1.3 \mathrm{~mm}, \mathrm{~V} 9.0 \mathrm{~mm}$ & $2.0 \mathrm{~mA}$ for $20 \mathrm{sec}$ \\
& 1) L $0.5 \mathrm{~mm}, \mathrm{AP}+1.3 \mathrm{~mm}, \mathrm{~V} 4.5 \mathrm{~mm}$ & $2.0 \mathrm{~mA}$ for $20 \mathrm{sec}$ \\
Hippocampus & 1) L $2.0 \mathrm{~mm}, \mathrm{AP}-3.5 \mathrm{~mm}, \mathrm{~V} 3.7 \mathrm{~mm}$ & $2.0 \mathrm{~mA}$ for $30 \mathrm{sec}$ \\
& 2) L $3.0 \mathrm{~mm}, \mathrm{AP}-5.0 \mathrm{~mm}, \mathrm{~V} 3.7 \mathrm{~mm}$ & $2.0 \mathrm{~mA}$ for $30 \mathrm{sec}$ \\
\hline
\end{tabular}

The skull was aligned with lambda and bregma horizontal and anterior-posterior coordinates were measured from bregma, while vertical coordinates were measured from the skull.

The rats with sulcal cortex lesions were aphagic for 6 to 10 days and were gastrically intubated until they began to eat. Postoperative recovery was at least 6 weeks for all groups, at which time all animals were healthy.

\section{Procedure}

The procedure was based on one used previously (Lehr \& Nachman, 1973; Nachman \& Ashe, 1973). Briefly, animals were maintained on a $231 / 2-h$ water-deprivation schedule for 10 days prior to testing. Water intake was recorded for the first $15 \mathrm{~min}$ of their daily $1 / 2-h$ drinking period, which took place in the home cage. Actual testing was composed of 6 test days. Days 1, 2, 4, and 5 were identical to the 10 adaptation days (i.e., water only), while on Days 3 and 6 the animals were given a $.12-\mathrm{M} \mathrm{LiCl}$ solution instead of water for $15 \mathrm{~min}$ followed by $30 \mathrm{~min}$ access to tap water. The measure of taste aversion was the amount of poison $(\mathrm{LiCl})$ consumed on Day 6.

Pilot work had suggested that neither IP injections of $\mathrm{LiCl}$ in the absence of flavor-illness association nor presentation of $\mathrm{NaCl}$ and no poison produced an aversion to drinking $\mathrm{LiCl}$ on later presentation. Therefore, no rats were specifically run to control for the possible confounding of the taste cue (the "CS") and the sickness (the "US").

At the completion of the study the rats were sacrificed with an overdose of sodium pentobarbital and intracardially perfused with normal saline followed by $10 \%$ Formalin in saline. The brains were removed, photographed, embedded in celloidin and cut at $\mathbf{2 6}$ microns. Every fifth section was mounted on slides and stained with cresyl violet.

\section{RESULTS}

\section{Anatomical}

The extent of the lesions is shown in Figure 1. Reconstructions are presented for representative subjects whose behavioral scores fell within the interquartile range of their respective groups. Lesions to the medial or sulcal prefrontal cortex removed all of the cortical projection areas of the dorsomedial thalamic nucleus (MD). The sulcal lesions produced mild degeneration in the medial portion of MD and occasionally produced additional degeneration in the ventral portion of the ventral lateral thalamic nucleus. The medial frontal lesions produced mild degeneration in the lateral portions of MD and occasionally in the anterior medial thalamic nucleus. The lesions in the cingulate cortex included all of the cingulate cortex and varying amounts of damage to the corpus callosum. In addition, there was complete bilateral interruption of the cingulum bundle at about the level of the anterior genu of the corpus callosum, thus guaranteeing that the thalamic input to the cingulate cortex was completely interrupted. Severe retrograde degeneration appeared in the dorsal and ventral anterior thalamic nuclei in nearly all cases, severe to moderate degeneration occurred in the medial anterior and dorsal lateral nucleus, and moderate degeneration occurred in lateral MD and the medial ventral nucleus. A comparison of the pattern of degeneration for the medial frontal and cingulate groups indicates that there was some overlap in some of the lesions. Lesions to the caudate nucleus included up to $59 \%$ of the nucleus and produced degeneration in MD as well as thalamic nucleus anterior ventralis. The damage to the medial thalamus included the dorsomedial nucleus and periventricular nuclei bilaterally in all cases, as well as occasional damage to the stria medularis or habenulae. The amygdala group suffered generally complete bilateral destruction of the medial amygdala but there was some sparing laterally, particularly the basolateral nucleus. The septal lesions were characterized by complete destruction of the medial septal nuclei and bilateral sparing of the ventral portion of the lateral septal nucleus. In addition, there was slight damage to the dorsal fornix in all of the animals. The hippocampal lesions destroyed $80 \%-90 \%$ of the structure, with some sparing of the most anterior ventral portion of all cases. There was, in addition, slight damage to the corpus callosum and overlying cortex.

\section{Behavioral}

The groups with lesions to the septum or amygdala were both impaired at taste aversion (Day 6, second presentation of $\mathrm{LiCl}$ ) behavior, as is illustrated in Figure 2. No other lesion groups differed significantly from controls. Analysis of variance revealed a significant $\mathrm{LiCl}$ effect $(F=19.3, p<.01)$ and a lesion effect $(F=15.2$, $p<.01)$, while the interaction was not significant. Appropriate follow-up tests (Tukey's test) revealed that the septal and amygdala groups differed significantly from all other groups in the amount of $\mathrm{LiCl}$ consumed on both presentations $(\mathrm{p}<.01)$; no other comparisons on these days were statistically reliable. On days on which water only was presented (Days 1, 2, 4, and 5), 


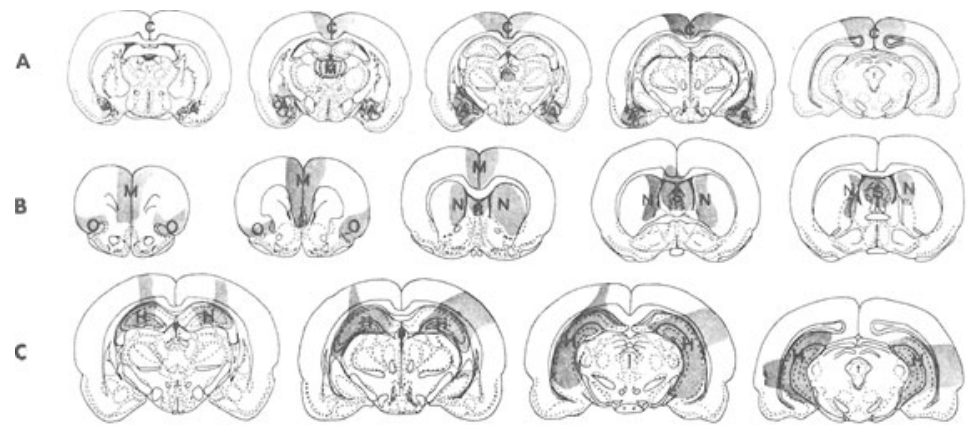

Figure 1. (a) Coronal sections through representative lesions in the cingulate cortex (C), medial thalamus (M), and amygdala (A) superimposed on a single series of sections. Note that no single rat got all these lesions. Figure adapted from König \& Klippel (1963). (b) Coronal sections through representative lesions in the medial frontal cortex (M), orbital frontal (Sulcal) cortex (O), caudate nucleus (N), and septum (S), superimposed on a single series of sections. Note that no single rat got all of these lesions. (c) Coronal sections through a representative lesion in the hippocampus.

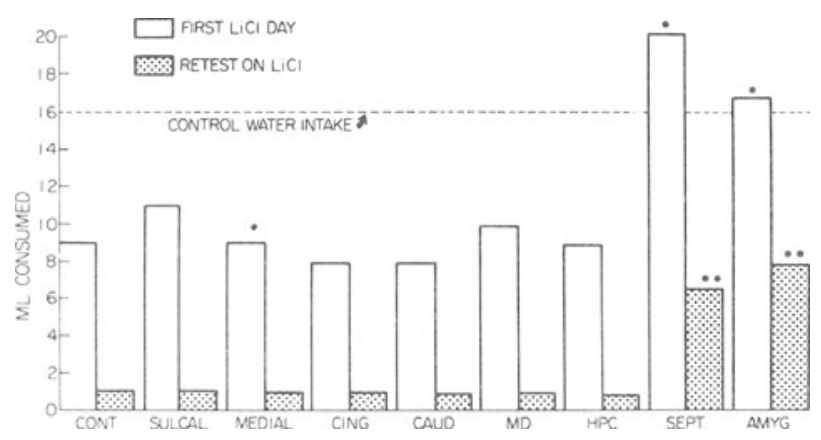

Figure 2. Comparison of poison $(\mathrm{LiCl})$ consumed on the initial presentation and retest in each group. The * and ** indicate that the septal and amygdala groups differed significantly $(p<.01)$ from all other groups on both the first and second $\mathrm{LiCl}$ tests, respectively. The $\mathrm{LiCl}$ and test data for all groups except the amygdala and septal groups were rounded to the nearest $\mathrm{ml}$ and mostly reflect spillage. All groups did not drink exactly $1 \mathrm{ml}$. The control water intake indicates the mean water intake of the control group on Days 1, 2, 4, and 5 .

the septal group drank significantly more water $(\mathrm{p}<.01)$ than any of the other groups. This result suggested that the increased intake of $\mathrm{LiCl}$ by the septal group could have resulted from polydipsia, rather than a deficit in taste aversion learning per se. Therefore, the data were transformed into preference scores (ratio of $\mathrm{LiCl}$ intake on Days 3 and 6 to water intake on Days 2 and 5, respectively) to examine this possibility. These data are shown in Table 2, where it can be seen that even when the data are transformed in an attempt to control for baseline water intake, both the septal and amygdala groups consumed relatively more $\mathrm{LiCl}$ on both test days. Analyses of variance revealed a significant lesion effect on both poison days $(\mathrm{F}=17.9, \mathrm{p}<.01 ; \mathrm{F}=33.0, \mathrm{p}<.01)$. However, follow-up tests (Tukey's) revealed that the septal group consumed significantly more poison on both test days than all groups except the amygdala group, which differed significantly from all other groups. These latter data are important because they indicate that the lesion effect in the amygdala and septal group is not of equal magnitude when one controls for the increased water intake by the septal group.

\section{DISCUSSION}

Lesions to the septum and amygdala impaired taste aversion learning while lesions to the prefrontal cortex, medial thalamus, caudate nucleus, cingulate cortex, and hippocampus did not. Several other lesions are reported to disrupt taste aversion learning, including ventral medial hypothalamus (Gold \& Proulx, 1972; but see Weisman, Hamilton, \& Carlton, 1972, who found facilitated taste-illness learning), olfactory bulbs (Hankins et al., 1973), and gustatory cortex (Braun, Slick, \& Lorden, 1972; Lorden, 1976). The behavior shown by the rats with orbital frontal and medial frontal lesions (Divac, Gade, \& Wikmark, 1975) and amygdala lesions (McGowan et al., 1972; Nachman \& Ashe, 1974) is consistent with earlier reports, while that shown by the rats with hippocampal lesions is consistent with some reports (Krane, Sinnamon, \& Thomas, 1976; Miller, Elkins, Fraser, Peacock, \& Hobbs, 1975; Murphy \& Brown, 1974) but not with Best and Orr (1973). However, the conditioning paradigms differ considerably in the latter cases and this appears to be important (Krane et al., 1975). Some procedural differences that probably affect the performance of brain-damaged animals in baitshyness studies could include: (1) The toxin used to induce illness and (2) the actual taste of the novel food. $\mathrm{LiCl}$ and apomorphine are both commonly used but have quite different effects on the organism besides just inducing illness. For example, apomorphine is thought to affect dopamine transmission, while $\mathrm{LiCl}$ is not known to have this effect. Braun et al. (1972) and Lorden (1976) found that damage to the gustatory cortex impaired learning of a sweet-illness association but failed to disrupt learning of illness associations to quinine, sodium chloride, quinine hydrochloride, and hydrochloride acid solutions. Similarly, hamsters with amygdala lesions are impaired when sweet is the novel taste but not when salty is the novel taste (Shipley \& Kolb, in press). (3) Studies which employ a twobottle preference (water vs. flavor) may find different results than those employing a single choice, as in the present study (see Krane et al., 1976). In the latter case the animals must totally inhibit drinking; in the former they do not. This is presumably very important when studies confound aversion measures and polydipsia, as was the case for the group with

Table 2

Mean Preference Scores

\begin{tabular}{lcc}
\hline & $\begin{array}{c}\mathrm{LiCl} \mathrm{l} / \\
\text { Day } 2 \mathrm{H}_{2} \mathrm{O}\end{array}$ & $\begin{array}{c}\mathrm{LiCl} 2 / \\
\text { Day } 5 \mathrm{H}_{2} \mathrm{O}\end{array}$ \\
\hline Control & .73 & .10 \\
Sulcal & .79 & .11 \\
Medial & .71 & .10 \\
Cingulate & .60 & .08 \\
Caudate & .62 & .08 \\
MD & .76 & .09 \\
Hippocampus & .69 & .11 \\
Septal & $1.10^{*}$ & $.29^{*}$ \\
Amygdala & $1.28^{* *}$ & $.61^{* *}$ \\
\hline
\end{tabular}

*Significantly higher than all groups except amygdala $(p<.01)$. **Significantly higher than all groups $(p<.01)$. 
septal lesions in the current study. (4) Whether one is testing learning or remembering is probably also important, as Schwartz and Teitelbaum (1974) have recently found that lesions to the lateral hypothalamus disrupted postoperative learning of baitshyness problerns but, on the other hand, the lesions failed to disrupt similar problems that were learned preoperatively. The importance of these variables in interpreting the results reported here, as well as elsewhere, remains to be properly examined.

Two important questions arise: (1) To what extent can we conclude that the data reported here and elsewhere represent a disruption of taste-illness association, and (2) what implications have our findings for evaluation of neural models of taste aversion learning?

Learning is always inferred from behavior and it is tempting to conclude that the lesions are disrupting stimulus-response (taste-poison) associations. However, a cautionary note is advisable here since these might actually result from other factors, including sensory or motivational alterations, rather than an associational blockage. While there is little reason to believe that lesions of the septum or amygdala reduce taste sensitivity or produce a general learning debility, a "motivational" deficit is not so easily dismissed, particularly for the group with septal lesions in the current study. These animals drank significantly more water than the other groups, so it is possible to argue that their impaired taste aversion learning, in part or in whole, is a consequence of increased water intake. However, analysis of preference scores suggested that when the increased water intake is controlled for there is still evidence that septal lesions produce a mild, but significant, impairment in taste aversion learning.

There are several difficulties in constructing a general framework which will organize the data on the neural mechanisms of taste aversion learning. Roth et al. (1973) suggested that it could result from damage to Teitelbaum's (1971) hypothetical encephalized eating system. However, the failure to find a deficit following lesions to the sulcal cortex (present study) or substantia nigra (Stricker \& Zigmond, 1974) presents a problem, since these lesions also severely disrupt ingestive behavior but do not alter taste aversion learning (present study; Stricker \& Zigmond, 1974). Another hypothesis is that the neural system mediating taste aversion learning is composed of those structures whose ablation disrupts both shock avoidance and regulatory ingestive behaviors. This position could account for all of the data in the present study (Olton, 1973), as well as for the behavior of rats with lesions in lateral hypothalamus (Runnels \& Thompson, 1969) and ventral medial hypothalamus (McNew \& Thompson, 1966). But this position is found wanting with respect to lesions to the olfactory bulbs or gustatory cortex, as lesions to these areas do not appear to alter food intake.

\section{REFERENCES}

Best: P. J., \& ORR, J. Effects of hippocampal lesions on passive avoidance and taste aversion conditioning. Physiology and Behavior, 1973, 10, 193-196.

Braun, J.J.. SLICK, T. B., \& LoRden, J. F. Involvement of gustatory neocortex in the learning of taste aversion. Physiology and Behavior, 1972, 9, 637-641.

Divac. I.. GadE, A..\& Wikmark, R. G. E. Taste aversion in rats with lesions in the frontal lobes: No evidence for interoceptive agnosia. Physiological Psychology, 1975, 3, 43-46.

Domesick. V. B. Projections from the cingulate cortex in the rat. Brain Research, 1969, 12. 296-320.

Gold, R. M., \& Proulx, D. M. Bait-shyness acquisition is impaired by VMH lesions that produce obesity. Journal of Comparative and Physiological Psychology, 1972, 79, 201-209.

Hankins, W. G., Garcia, J., \& Rusinak, K. W. Dissociation of odor and taste in baitshyness. Behavioral Biology, 1973, 8. 407-419.

König. J. F. R..\& KLIPPEL, D. The rat brain: A stereotaxic atlas of the forebrain and lower parts of the brainstem. Baltimore: Willians \& Wilkins, 1963.
Krane, R.. Sinnamon. H.. \& Thomas. G. Conditioned taste aversions and neophobia in rats with hippocampal lesions. Journal of Comparative and Phvsiological Psychology. 1976. 90, 680-693.

LeHR, P. P.. \& NAChman, M. Lateralization of learned taste aversion by cortical spreading depression. Physiology and Behavior, 1973, 10, 79-83.

LeOnard, C. M. The prefrontal cortex of the rat: I. Cortical projection of the mediodorsal nucleus. II. Efferent connections. Brain Research, 1969, 12, 321-343.

LORDEN, J. F. Effects of lesions of the gustatory neocortex on taste aversion learning in the rat. Journal of Comparative and Physiological Psychology. 1976, 90. 665-679.

McGowan, B. K.. Garcia, J., Ervin, F. R., \& Schwartz, J. Effects of septal lesions on bait-shyness in the rat. Physiology and Behavior, 1969, 4. 907-909.

McNew. J. J., \& Thompson, R. Role of the limbic system in active and passive avoidance conditioning in the rat. Journal of Comparative and Physiological Psychology. 1960. 61. 173-180.

Miller, C. R.. Elkins, R. L., Fraser, J., Peacock, L. J.. \& Hоввs. S. H. Taste aversion and passive avoidance in rats with hippocampal lesions. Physiological Psychology, 1975, 3. 123-126.

Miller. C. R.. Elkins, R. L., \& Peacock, L. J. Disruption of a radiation-induced preference shift by hippocampal lesions. Physiology' and Behavior. 1971, 6. 283-285.

Murphy, L. R..\& Brown. T. S. Hippocampal lesions and learned taste aversion. Physiological Psychology. 1974, 2. 60-64.

Nachman, M., \& Ashe, J. H. Learned taste aversions in rats as a function of dosage, concentration and route of administration of LiCl. Physiology and Behavior, 1973, 10, 73-78.

NACHMAN. M.. \& Ashe. J. H. Effects of basolateral amygdala lesions on neophobia. learned taste aversions, and sodium appetite in rats. Journal of Comparative, and Physiological Psyehology, 1974. 87, 022-643.

Nonneman. A. J.. Voigt, J.. \& Kolb. B. E. Comparisons of behavioral effects of hippocampal and prefrontal cortex lesions in the rat. Journal of Comparative and Physiological Psychology. 1974, 87, 249-260.

Orton, D. S. Shock-motivated avoidance and the analysis of behavior. Psychological Bulletin, 1973, 79, 243-251.

Roth. S. R.. Schwartz. M.. \& Teitelbaum, P. Failure of recovered lateral hypothalamic rats to learn specific food aversion. Journal of Comparative and Physiological Psychology, 1973, 83, 184-197.

Rozin. P. \& Kalat. J. W. Specitic hungers and poison avoidance as adaptive specializations of learning. Psychological Review', 1971. 78. 459-486.

Runnels, D., \& Thompson, R. Hypothalamic structures critical for the performance of a locomotor response in the rat. Brain Research, 1969, 13, 328-337.

Schwartz. M., \& Teitelbaum, P. Dissociation between learning and remembering in rats with lesions in the lateral hypothalamus. Journal of Comparative and Physiological Psychology. 1974, 87, 384-398.

Shipley, J. E. \& KolB, B. Neural correlates of species typical behavior in the Syrian golden hamster. Journal of Comparative and Physiological Psychology, in press.

Stricker. E. M.. \& Zigmond, M. J. Effects on homeostasis of intraventricular injections of 6-hydroxydopamine in rats. Journal of Comparative and Physiological Psychology, 1974, 86, 973-994.

Teitelbaum, P. The encephalization of hunger. In E. Stellar \& J. J. Sprague (Eds.). Progress in physiological psychology (Vol. 4). New York: Academic Press. Pp. 319-350.

Weisman, R. N., Hamilton, L. W., \& Carlton, P. L. Increased gustatory aversion following VMH lesions in rats. Physiology and Behavior, 1972, 9. 801-904.

(Received for publication July 12, 1977.) 